\title{
BIOLOGICAL METABOLITES RECOVERY FROM BEVERAGE PRODUCTION SOLID RESIDUES THROUGH ACIDOGENIC FERMENTATION
}

\author{
Francesca Girotto ${ }^{1}$, Sigrid Kusch ${ }^{2}$ and Maria Cristina Lavagnolo $1, *$ \\ 1 University of Padova, Department of Civil, Environmental and Architectural Engineering, via Marzolo 9, 35131, Padova, Italy \\ ${ }^{2}$ University of Southampton, Water and Environmental Engineering Group, S017 1BJ Southampton, United Kingdom
}

Article Info:
Received:
6 October 2018
Revised:
14 December
Accepted:
11 January 2019
Available online:
30 January 2019
Keywords:
Spent coffee grounds
Orange peels
Brewers' spent grains
Biorefinery
Acidogenic fermentation

Article Info:

October 2018

11 January 2019

eywords:

Orange peels

Biorefinery

Acidogenic fermentation

\begin{abstract}
Acidogenic fermentation was applied to evaluate the potential recovery of biological monomers as precursors in bio-plastic production. Three residual organic substrates from high-volume beverage sectors (coffee, orange juice, beer) were assessed: spent coffee grounds (SCG), orange peels (OP), and brewers' spent grains (BSG). Batch fermentation tests were set up. SCG and OP were studied as single substrates and combined to evaluate yields of target monomers (volatile fatty acids, ethanol, lactate) and to reveal interactions between the matrixes. $\mathrm{NaOH}$ pre-treatment was applied to SCG to enhance disruption of the lignocellulosic cell wall. BSG was studied without pre-treatment and following acid or alkaline pre-treatment, with acidogenic fermentation being initiated with two different initial pH values $(7 ; 9)$. Acetogenic fermentation was achieved with all substrates, although with different yields of target monomers. In terms of total biological metabolite production, following alkaline pre-treatment, OP and BSG, both fermented at an initial $\mathrm{pH} 9$, showed the best performance, yielding $62.6 \mathrm{~g}$ and $62.0 \mathrm{~g}$ target monomers per litre substrate. For all substrates, acetic and butyric acids were the most abundant products. In the case of OP fermentation, butyrate accounted for $57 \%$ (35.8 g/L) of the total. The BSG test with the highest total yield also achieved the highest acetate yield $(36.7 \mathrm{~g} / \mathrm{L})$. The results confirm that OP and BSG should be considered a priority sustainable feedstock for the supply of biological monomers, particularly if polyhydroxyalkanoates are to be produced. SCG are better suited to aceto-oriented approaches, such as the production of polyvinyl acetate.
\end{abstract}

\section{INTRODUCTION}

Under a circular economy approach, by-products occurring in production chains should preferentially be valorised before considering them a waste to be disposed of, and beverage by-products are no exception. In Italy, the most commonly consumed drinks are coffee and beer (throughout the whole country) and orange juice (particularly in the South where the climate favours cultivation of these citrus fruits). Each year, more than 300 million $\mathrm{kg}$ coffee beans (roasted coffee weight), 1,880 million litres beer, and 118 million litres orange juice are consumed in Italy alone (Statista, 2018). The production of industrial coffee and orange juice is increasing yearly. Bean-to-cup coffee machines and fresh orange juice dispensers are two of the most widely diffuse beverage machines in offices, bars and restaurants worldwide. They provide fresh drinks with a minimum effort, and are therefore being widely distributed, even at ready-to-go-snack areas in many cities.

\section{Coffee production residues}

Coffee is the world's second most widely traded commodity after oil and the most renowned drink worldwide (Girotto et al., 2017c). The International Coffee Organization (2018) estimated global coffee production at 158.56 million bags (one bag $=60 \mathrm{~kg}$ ) in $2017 / 18$. During 'fruit to cup' transformation of coffee beans, the processing and utilization steps generate huge quantities of wastes, such as spent coffee grounds (SCG) and coffee silver skin (Mussatto et al., 2011; Karmee, 2017). Park et al. (2016) reported that approximately 5.8 million tonnes SCG are generated worldwide every year as municipal solid waste. Furthermore, SCG represent a highly versatile residue which is perfectly suited to a biorefinery approach when used as a resource for fuels, biopolymers, biosorbents, activated carbons, polyols, polyurethane foams, carotenoids, antioxidants, and composites production (Karmee, 2017). Girotto et al. (2017c) investigated the advantages and chal- 
lenges of a series of different SCG valorisation pathways. Research into biopolymer production is still ongoing and the specific use of SCG as a substrate has not yet been fully addressed. As an example, polyphenol content may compromise the result outputs; however, when isolated from spent coffee grounds prior to hydrolytic reaction, may result in a $25 \%$ increase in polyhydroxyalkanoates yield (Karmee, 2017; Obruca et al., 2015).

SCG is a lignocellulosic material and, with a view to exploiting this residue as a source of energy, a series of pre-treatments (Girotto et al., 2017d; Kovalcik et al., 2018), including acidic, alkaline, oxidative, steam explosion, and thermo-chemical pre-treatments was applied, with alkaline pre-treatment proving to be one of the best performing applications (Chaturvedi and Verma, 2013).

\section{Residues from orange juice production}

The international trade of citrus fruits, including both fresh and processed (e.g. juices) fruits, represents the most economically viable fruit market. The most abundant citrus fruits are oranges (El Kantar et al., 2018) which are mainly cultivated in Brazil, United States, Mexico, China, and in the Mediterranean basin (Zema et al., 2018). According to the Food and Agriculture Organization of the United Nations, the world production of orange juice is on a constant increase, reaching 71 million tonnes in 2014 (FAO, 2015). Industrial processing generates large amounts of solid residues, mainly peels, which represent over $50-60 \%$ (wb) of the fruit itself (Calabrò et al., 2018a; Zema et al., 2018). Several approaches have been investigated in managing these wastes. Fresh orange peels (OP) were largely used in the past as cattle feed due to the positive effects produced on lactation in cows (Calabrò et al., 2018a); however, environmental and economic concerns (such as percolation, odour emissions, insufficient demand) have limited use of this solution (Zema et al., 2018). Currently however, the majority of OP generated yearly are not valorised and require appropriate treatment or disposal. OP are composted to produce fertilizers (Calabrò et al., 2018a), alcoholically fermented to obtain bioethanol, anaerobically digested to recover biogas (Zema et al., 2018) or landfilled (Calabrò et al., 2018b). However, because of the low pH (around 3-5) and fast biodegradation rate, citrus waste is generally not well accepted in composting plants and may cause anaerobiosis problems in the compost piles (Martin et al., 2018; Ruiz and Flotats, 2014). Solid state fermentation to recover enzymes for use in the production of high-value materials is not yet mature or sufficiently economically sustainable to be implemented on a full-scale (Calabrò et al., 2018b). Indeed, to date, anaerobic digestion for biogas production been proved to be one of the most promising treatment processes for use in the recovery of bioenergy; the main obstacle is the high content of essential oils (up to 0.4-0.5\% w/w) (Zema et al., 2018; Kimball, 1999), mainly composed of D-limonene (83-97\%) (Calabrò et al., 2018b; Bicas et al., 2008), which is toxic for microorganisms (Calabrò et al., 2018a; Zema et al., 2018) and may decrease the biogas yield. Pre-treatments (e.g. size reduction, steam distillation, hexane extraction, addition of enzymes, steam explosion and combination of steam explosion, and dilute acid hydrolysis) have been tested in extraction of the oils before digesting the substrate, however, the economic viability of this type of pre-treatment is difficult to achieve (Zema et al., 2018; Koppar and Pullammanappallil, 2013).

OP however represent an excellent source for high-value biomolecules like polyphenols, flavonoids, essential oils, fibres, and sugars (El Kantar et al., 2018; Martin et al., 2018). OP have also been shown to provide an environmentally sustainable option when used in the catalysed hydrolysis of esters (da Silva et al., 2016) or, in general, as a cost-effective enzyme feedstock (mainly pectinase and lipase) (Qureshi et al., 2017).

To date the possibility of valorising OP to recover biomolecules by means of acidogenic fermentation remains to be investigated; however, the high potential of this approach has already been proven for other organic substrates (Girotto et al., 2017a). Acidogenic fermentation enables the recovery of monomers capable of acting as precursors in bio-plastic production.

\section{Beer}

Beer is the fifth most widely consumed beverage worldwide after tea, carbonated drinks, coffee, and milk, with an average consumption of 23 litres per capita every year (Fillaudeau et al., 2006). It has been estimated that the world production of beer exceeded 1.34 hectolitres in 2002 (Fillaudeau et al., 2006; Aliyu and Bala, 2011). Several by-products are generated during the beer production process (mainly spent grains, spent hops, and surplus yeast). Brewers' spent grains (BSG) are the main by-product of the brewing industry, representing approximately $85 \%$ of the total by-products (Mussatto et al., 2006). BSG are produced during the mashing process, one of the first brewery operations undertaken to solubilise the malt and cereal grains and ensure adequate extraction of the wort (Fillaudeau et al., 2006; Aliyu and Bala, 2011). Approximately 3.4 million tonnes of BSG are generated in the EU every year (Stojceska et al., 2008; Aliyu and Bala, 2011).

A typical production of BSG is from barley, the most world's common cereal after wheat, corn, and rice, mainly used in the beer production process and as animal feed (Kendal, 1994; Mussatto and Roberto, 2004). Barley grains are rich in starch and proteins and are made up of three main parts: the germ (embryo), the endosperm (comprising the aleurone and starchy endorsperm), and the grain coverings. The latter can be divided into three fractions: the seed coat, the innermost layers surrounding the aleurone, and the pericarp layers, which overlay the seed coat and are covered by the husk (Kunze, 1996; Mussatto et al., 2011). BSG typically have a moisture content of more than $75 \%$, while the dry matter is made up of approx. $20 \%$ protein and $70 \%$ fibre (Akunna, 2015; Mussatto et al., 2006). This lignocellulosic material (fibre part) contains approximately $17 \%$ cellulose, $28 \%$ hemicellulose, and $28 \%$ lignin (Mussatto et al., 2006).

Several attempts have already been made to determine the most convenient potential means of utilising BSG as animal feed, as a nutritional ingredient, in the production of value-added compounds (such as xylitol, ethanol, and lactic acid), in microorganism cultivation, mushroom culti- 
vation, or as raw material for the extraction of compounds including sugars, proteins, acids, and antioxidants (Aliyu and Bala, 2011; Mussatto et al., 2006). BSG have also been applied in the production of enzymes, in the immobilisation of various toxic substances, and in the adsorption of organic materials from effluents (Mussatto et al., 2006; Aliyu and Bala, 2011).

\section{Aim of the study}

The aim of this study was to evaluate the potential recovery of biological monomers (to be used in bio-plastic production) from the acidogenic fermentation treatment of three residual organic substrates, SCG, OP, and BSG, originating from the production of the three above-mentioned high-volume beverages: coffee, orange juice, and beer. Acidogenic batch tests were performed to study the performance of the substrates with a view to comparing the recoverable quantities of relevant biological monomers (volatile fatty acids, ethanol, lactate).

From a practical point of view, since beer is produced in specialised locations and solid residues are collected separately, BSG were studied independently, while SCG and OP were studied together. SCG and OP were used as single substrates and as a mix of the two to compare the yields and evaluate any eventual positive or negative interaction between the matrixes.

SCG were pre-treated with sodium hydroxide $(\mathrm{NaOH})$ to enhance the disruption of the lignocellulosic cell wall. The use of a series of different pre-treatments to solubilise SCG fibres has been reported in literature, and alkaline reagents have been found more effective compared to acid or oxidative reagents (Taherzadeh et al., 2008; Gáspár et al., 2007); $\mathrm{NaOH}$ in particular has been reported as having a stronger action than potassium hydroxide or lime (Yang et al., 2012).

In the case of BSG, alkaline pre-treatment is a predominantly selected processing (Ravindran et al., 2012). Nevertheless, Macheiner et al. (2003) reported highly improved hydrolyzation outputs following acid pre-treatment using hydrochloric acid $(\mathrm{HCl})$. Therefore, in this study BSG were subjected to both acid and alkaline pre-treatment. BSG fermentation tests were performed using untreated substrate (raw), substrate that had undergone acid pre-treatment, and substrate that had undergone alkaline pre-treatment.

All samples, with the exception of BSG after acid pre-treatment, were fermented at an initial $\mathrm{pH}$ 9. The choice of operating acidogenic fermentation at initial $\mathrm{pH} 9$ was based on the findings of previous studies (Lavagnolo et al., 2018; Girotto et al., 2017a), with this pH level also being positively used elsewhere in literature (i.a. Dahiya et al., 2015). In the case of acid-pre-treated BSG, the initial fermentation $\mathrm{pH}$ was adjusted to 7 rather than 9 in order to limit the amounts of reagents required to modify $\mathrm{pH}$ to a reasonable level. To identify any effect of the initial $\mathrm{pH}$ value, raw BSG (without pre-treatment) were fermented at both $\mathrm{pH} 9$ and 7.

\section{MATERIALS AND METHODS}

To investigate the quantities of biological metabolites that could be recovered from acidogenic fermentation treat- ment, dark fermentation batch tests were implemented. Research was carried out in two experimental runs. The first trial used spent coffee grounds (SCG) and orange peels (OP) both as single substrates and mixed together; SCG were pre-treated with $\mathrm{NaOH}$ on the basis of previous results obtained by Girotto et al. (2017b). The second trial used brewer spent grains (BSG) as substrate and evaluated the effect of acid and alkaline pre-treatment in the presence of two different initial fermentation $\mathrm{pH}$ values, namely 7 and 9 .

Bio-hydrogen production during acidogenic fermentation was monitored as an indicator of when to stop the test before it entered too far into the acetogenic phase. Indeed, once a plateau was reached, the fermented broth composition was evaluated in terms of ethanol, VFAs, and lactate.

\subsection{Substrates and inoculum}

SCG were collected after the brewing of coffee using a moka coffee pot from the Environmental Engineering Laboratory of Padova University. Ten moka pots (with a serving size of 3 persons) were prepared using packed 100\% Arabica ground coffee, the SCG were collected each time and stored in a fridge until the time of sampling of the desired amount. Conversely, OP were removed from the orange juice machine located in the University canteen and crushed into small pieces using a kitchen miller. Fresh BSG (barley origin) were collected from a brewery located in $\mathrm{Pa}$ dova, Italy.

SCG, OP, and BSG were tested for Total Solids (TS), Volatile Solids (VS), Total Carbon (TC), Total Nitrogen (TN), and fibres (Table 1).

Granular sludge ( $66.5 \mathrm{gVS} / \mathrm{L}, \mathrm{pH}=9)$ collected from a full-scale Upflow Anaerobic Sludge Blanket (UASB) digester in the same brewery located in Padova, was used as inoculum for the acidogenic fermentation tests. Undefined mixed cultures are usually preferred as an inoculum due to the metabolic flexibility conferred by the numerous elements involved (Agler et al., 2011) and, therefore, their ability to tolerate the complexity and variability of substrates and process conditions. Indeed, the synergistic effect between the various microorganisms may improve acidogenic fermentation yields (Yin et al., 2016).

Prior to fermentation tests, the inoculum was thermally

TABLE 1: Characteristics of spent coffee grounds (SCG), orange peels (OP), and brewers' spent grains (BSG) used in the experiment.

\begin{tabular}{l|c:ccc} 
& SCG & OP & BSG \\
Parameter & $\%$ & $\%$ & $\%$ \\
\hline Total solids (TS) (wb) & 38.8 & 21.9 & 18.6 \\
\hdashline Volatile solids (VS) (wb) & 38.3 & 21.3 & 17.9 \\
\hdashline Total carbon (TC) (db) & 57.9 & 39.2 & 44.3 \\
\hdashline Total nitrogen (TN) (db) & 2.3 & 8.3 & 10.2 \\
\hdashline Cellulose $(\mathrm{db})$ & 23.5 & 12.1 & 12.3 \\
\hdashline Hemicellulose $(\mathrm{db})$ & 26.4 & 2.2 & 26.2 \\
\hline Lignin $(\mathrm{db})$ & 14.3 & 1.8 & 3.4 \\
\hline
\end{tabular}

Note - wb: wet basis; $d b$ : dry basis 
pre-treated for 30 minutes at $80^{\circ} \mathrm{C}$ to inhibit methanogenic archaea and stop the anaerobic process at the acidogenic fermentation step (Alibardi et al., 2012).

\subsection{Substrates pre-treatments}

\subsubsection{SCG alkaline pre-treatment}

SCG were mixed evenly with a $\mathrm{NaOH}$ solution, $8 \% \mathrm{w} / \mathrm{w}$ (Girotto et al., 2017b), at a pH higher than 12. The $\mathrm{NaOH}$ soaked SCG were kept at constant room temperature (20 $\pm 0.5^{\circ} \mathrm{C}$ ) in $250 \mathrm{~mL}$ glass bottles for $24 \mathrm{~h}$. At the end of the pre-treatment, samples were taken for compositional analysis before acidogenic fermentation tests. At the end of the $24 \mathrm{~h}$ alkaline pre-treatment, the $\mathrm{pH}$ had decreased from $>12$ to 9 , and this $\mathrm{pH}$ level was equal to the initial $\mathrm{pH}$ selected for the subsequent fermentation phase.

\subsubsection{BSG acid and alkaline pre-treatments}

To compare acid and alkaline pre-treatments, a sample of BSG was mixed evenly with an $\mathrm{HCl}$ solution (37\% concentrated) at a $\mathrm{pH}$ lower than 3 , whilst another was mixed with a sodium hydroxide $(\mathrm{NaOH})$ solution (reaching $8 \%$ $\mathrm{w} / \mathrm{w}$ ) at a $\mathrm{pH}$ higher than 12 . The $\mathrm{HCl}$ - and $\mathrm{NaOH}$-soaked BSG were kept at constant room temperature $\left(20 \pm 0.5^{\circ} \mathrm{C}\right)$ in $250 \mathrm{~mL}$ open glass bottles for $24 \mathrm{~h}$ without stirring. At the end of the pre-treatment, samples were taken for compositional analysis before acidogenic fermentation tests.

\subsection{Fermentation tests}

The experimental design was established to compare the outputs of acidogenic fermentation of pre-treated SCG and OP both alone and mixed together (1:1 on a VS basis), in addition to recording the effects of acid and alkaline pre-treatments and of two different initial $\mathrm{pH}$ values on the acidogenic fermentation of BSG. Initial pH values of 7 and 9 were used and were tested on BSG with and without pre-treatment.

Acidogenic fermentation batch tests were carried out using $500 \mathrm{~mL}$ glass bottles sealed with a silicon plug and a working volume of $250 \mathrm{~mL}$. Substrate concentration was $10 \mathrm{gVS} / \mathrm{L}$ in each bottle. Inoculum was added to reach an S/I ratio of $6 \mathrm{gVS} / \mathrm{gVS}$ (Girotto et al., 2017a). All fermentation tests were performed in triplicate.

In all bottle-reactors, $\mathrm{pH}$ was adjusted after inoculum addition. $\mathrm{A} \mathrm{pH}$ value equal to 9 was shown to enable the best acidogenic fermentation condition in previous studies (Girotto et al., 2017a; Lavagnolo et al., 2018).

For the first trial (SCG and OP), pH was adjusted to 9 using $\mathrm{NaOH}$ or $\mathrm{HCl}$ according to the specific need (see Table 2).

For the second series of tests (with BSG), the pH of BSG samples originating from acid pre-treatment was adjusted to 7 by adding $\mathrm{NaOH}$, while the $\mathrm{pH}$ of samples deriving

TABLE 2: Initial operative conditions of acidogenic fermentation batch tests for spent coffee grounds (SCG) and orange peels (OP).

\begin{tabular}{c|c:c:c} 
Run & Pre-treatment $(\mathbf{p H})$ & Initial $\mathbf{p H}$ & S/I (gVS/gVS) \\
\hline SCG & Alkaline $(>12)$ & 9.0 & 6.0 \\
\hdashline OP & none & 9.0 & 6.0 \\
\hdashline SCG+OP & Alkaline only for SCG (>12) & 9.0 & 6.0 \\
\hline
\end{tabular}

from alkaline pre-treatment was adjusted to 9 by the addition of $\mathrm{HCl}$ (see Table 3). Samples with pre-treated BSG are referred to as BSG_a-s and BSG_b-n, reflecting both the pH characteristics during pre-treatment (a for acid, $b$ for basic) and the initial $\mathrm{pH}$ values of fermentation tests (s for seven, $\mathrm{n}$ for nine). Samples with raw BSG (without pre-treatment) are referred to as BSG_r-s and BSG_r-n.

The bottles were flushed with $\mathrm{N}_{2}$ gas for 3 minutes to ensure anaerobic conditions and incubated at a temperature of $35 \pm 1^{\circ} \mathrm{C}$. Liquid samples were collected at the end of the tests (i.e. after reaching the plateau in $\mathrm{H}_{2}$ production) and analysed for the concentration of ethanol, VFAs (acetate, propionate, butyrate, valerate) and lactate.

\subsection{Analytical methods}

TS, VS, pH, TC, and TN were analysed by standard methods (APHA/AWWA/WEF, 2002); hemicellulose, cellulose, and lignin content were evaluated following the crude fibre procedure of AOCS (Firestone, 1994).

Following pre-treatments, to better assess the impact produced by addition of $\mathrm{HCl}$ (applied only to BSG) and $\mathrm{NaOH}$ (applied both to SCG and BSG) in terms of cell wall breakdown, further to evaluating changes in fibre concentration, dissolved organic carbon (DOC) values were analysed using a TOC analyser (TOC-V CSN, Shimadzu) after filtration of liquid pre-treated samples at $0.45 \mu \mathrm{m}$.

The volume of gas produced during fermentation was measured using the water displacement method (Alibardi et al., 2012). $\mathrm{H}_{2}$ and $\mathrm{CO}_{2}$ concentrations in the gas were measured using a gas chromatograph HP5890 (Hewlett Packard, USA) equipped with thermal conductivity detector (TCD), HP-MOLSIV and HP-PLOT U columns, and nitrogen as carrier gas.

Volumes of $\mathrm{H}_{2}$ produced in the time interval between each measurement $[\mathrm{t}-(\mathrm{t}-1)]$ were calculated using a model taking into consideration gas concentration at time $t$ and time $t-1$, together with the total volume of gas produced at time $t$, the concentration of specific gas at times $t$ and $t-1$, and the volume of head space of reactors (Van Ginkel et al., 2005). The following equation was applied:

$V C, t=c C, t * V G, t+V H^{*}(c C, t-c C, t-1)$

where:

$\mathrm{VC}, \mathrm{t}=$ volume gas component of interest (hydrogen) produced in the interval between $\mathrm{t}$ and $\mathrm{t}-1$

$\mathrm{cC}, \mathrm{t}, \mathrm{cC}, \mathrm{t}-1$ = concentrations gas component of interest (hydrogen) measured at times $t$ and $t-1$

$V G, t=$ volume of gas produced between time $t$ and $t-1$

$\mathrm{VH}=$ volume of the headspace of reactors.

TABLE 3: Initial operational conditions of acidogenic fermentation batch tests for brewers' spent grains.

\begin{tabular}{c|c|c|c} 
Run & Pre-treatment (pH) & $\begin{array}{c}\text { Initial pH } \\
\text { Seven-Nine }\end{array}$ & S/l (gVS/gVS) \\
\hline BSG_a-s & Acid (<3) & 7.0 & 6.0 \\
\hline BSG_r-s & none & 7.0 & 6.0 \\
\hline BSG_b-n & Alkaline $(>12)$ & 9.0 & 6.0 \\
\hline BSG_r-n & none & 9.0 & 6.0 \\
\hline
\end{tabular}


Data on $\mathrm{H}_{2}$ production are expressed at a temperature of $0^{\circ} \mathrm{C}$ and pressure of $1 \mathrm{~atm}$ (Normal conditions).

To analyse liquid samples obtained after fermentation for ethanol, VFAs (acetate, propionate, butyrate, and valerate), lactate and DOC analyses, samples were centrifuged at $6000 \mathrm{rpm}$ for 10 minutes, the supernatants were filtered using $0.45 \mu \mathrm{m}$ Phenex-RC filters (Phenomenex, Castel Maggiore, Italy), and stored at $-20^{\circ} \mathrm{C}$ until analysis. Ethanol, VFAs, and lactate concentrations, reported as $\mathrm{g} / \mathrm{L}$ of substrate in the 'Results' section, were analysed by injection into a high-performance liquid chromatography system (Shimadzu, Tokyo, Japan) complete with an LC 9A Shimadzu pump, a SIL 10A auto-sampler, and a RID-model Shimadzu 10A detector. Analytes separation was performed at $40^{\circ} \mathrm{C}$ using an Aminex HPX-87H column $(300 \times 7.8 \mathrm{~mm})$ and one pre-column (Bio-Rad, Hercules, CA, USA). DOC values in filtered samples after fermentation were again evaluated using a TOC analyser (TOC-V CSN, Shimadzu).

\section{RESULTS AND DISCUSSION}

\subsection{Impact of pre-treatment on chemical bonds in substrate matrix}

\subsubsection{Spent coffee grounds}

Alkaline pre-treatment helped to disrupt the chemical bonds within the solid matrix of the SCG. Indeed, $\mathrm{NaOH}$ addition led to an almost $362 \%$ increase in DOC compared to untreated samples (Table 4). This high increase was probably due to fine grinding of the substrate to obtain a sort of fine powder. As already demonstrated by similar studies (Girotto et al., 2017b; Pellera et al., 2016; Torres and Lloréns, 2008), $\mathrm{NaOH}$ contributes effectively to the hydrolysation of complex organic matter, resulting in transfer of the matter from the solid to the liquid phase.

\subsubsection{Brewers' spent grains}

Acid pre-treatment seemed to have little or no effect on DOC in comparison with untreated substrate, implying a failure of acid $\mathrm{pH}$ to contribute towards disrupting the chemical bonds within the solid matrix. On the contrary, $\mathrm{NaOH}$ addition led to a $69 \%$ increase in DOC compared to the untreated samples (Table 5).

The fibre composition values of both SCG and BSG subsequent to pre-treatments did not differ significantly from those of untreated substrates. This suggests the relevance of DOC as a parameter capable of effectively recognizing the strong action of $\mathrm{NaOH}$, likely over proteins and oil fractions, and in increasing the bioavailability of SCG and BSG
TABLE 4: Effect of 24h alkaline pre-treatment on the fibre composition of spent coffee grounds (SCG).

\begin{tabular}{c|c|c} 
Sample & SCG & SCG + NaOH \\
\hline Cellulose $(\% \mathrm{db})$ & $23.5 \pm 1.2$ & $23.8 \pm 0.9$ \\
\hdashline Hemicellulose $(\% \mathrm{db})$ & $26.4 \pm 0.8$ & $23.4 \pm 1.2$ \\
\hdashline Lignin $(\% \mathrm{db})$ & $14.3 \pm 0.9$ & $11.8 \pm 1.0$ \\
\hdashline DOC $(\mathrm{mgC} / \mathrm{L})$ & $655 \pm 12$ & $3025 \pm 47$ \\
\hline (mean value \pm standard deviation) &
\end{tabular}

TABLE 5: Effect of 24h acid and alkaline pre-treatments on the fibre composition of brewers' spent grains.

\begin{tabular}{|c|c|c|c|c|}
\hline Sample & $\begin{array}{c}\text { Cellulose } \\
(\% \mathrm{db})\end{array}$ & $\begin{array}{l}\text { Hemicellulose } \\
(\% \mathrm{db})\end{array}$ & $\begin{array}{l}\text { Lignin } \\
(\% d b)\end{array}$ & $\begin{array}{c}\mathrm{DOC} \\
(\mathrm{mgC} / \mathrm{L})\end{array}$ \\
\hline $\begin{array}{l}\text { BSG, raw (no } \\
\text { pre-treatment) }\end{array}$ & $12.3 \pm 1.4$ & $26.2 \pm 0.9$ & $3.4 \pm 0.8$ & $703 \pm 19$ \\
\hline $\begin{array}{l}\text { BSG, acid } \\
\text { pre-treatment }\end{array}$ & $12.5 \pm 1.6$ & $26.4 \pm 1.8$ & $3.6 \pm 0.9$ & $689 \pm 24$ \\
\hline $\begin{array}{l}\text { BSG, alkaline } \\
\text { pre-treatment }\end{array}$ & $12.9 \pm 1.2$ & $30.1 \pm 1.1$ & $5.5 \pm 1.1$ & $1187 \pm 29$ \\
\hline
\end{tabular}

(mean value \pm standard deviation)

for microorganisms involved in acidogenic fermentation, similar to the findings reported by Girotto et al. (2017b).

\subsection{Acidogenic fermentation}

\subsubsection{Spent coffee grounds and orange peels}

Following $24 \mathrm{~h}$ pre-treatment, $\mathrm{pH}$ dropped to 9 , underlining the excellent buffer capacity of SCG, which was likewise indicated by the almost neutral $\mathrm{pH}$ measured at the end of acidogenic fermentation tests (see Table 6). On the contrary, OP and OP+SCG samples were characterised by a slightly acid $\mathrm{pH}$ after fermentation. In each sample $\mathrm{pH}$ was adjusted to 9 at the beginning of the acidogenic fermentation tests. Indeed, a wide $\mathrm{pH}$ range of 3-9 has been reported as acceptable to different strains of fermentative bacteria (Ren et al., 2007), being much more adaptable than methanogenic bacteria (Pan et al., 2008).

Hydrogen production during acidogenic fermentation tests is shown in Figure 1. Hydrogen production reached a plateau after three days of acidogenic fermentation for all samples. Gas quality, tested by means of gas chromatography, confirmed that thermal pre-treatment of the inoculum had succeeded in inhibiting the archaea, since methane concentration was below $3 \%$ throughout the test (data not shown).

After three days (time required to reach the plateau in hydrogen production), the composition of fermented

TABLE 6: Change observed in pH between the beginning (Pstart) and the end (Pend) of pre-treatment, and prior (AFstart) and subsequent to (AFend) acidogenic fermentation tests.

\begin{tabular}{|c|c|c|c|c|c|c|}
\hline \multirow{2}{*}{ Sample } & \multirow{2}{*}{ Substrate pH } & \multirow{2}{*}{ Pre-treatment } & \multicolumn{4}{|c|}{$\mathrm{pH}$} \\
\hline & & & $\mathbf{P}_{\text {start }}$ & $\mathbf{P}_{\text {end }}$ & $\mathbf{A F}_{\text {start }}$ & $\mathbf{A F}_{\text {end }}$ \\
\hline SCG & $6.5 \pm 0.2$ & Alkaline & $6.5 \pm 0.2$ & $9.0 \pm 0.3$ & 9.0 & $6.5 \pm 0.2$ \\
\hline $\mathrm{OP}$ & $4.5 \pm 0.0$ & none & / & / & 9.0 & $5.0 \pm 0.1$ \\
\hline $\mathrm{SCG}+\mathrm{OP}$ & $5.5 \pm 0.2$ & Alkaline for SCG only & $6.5 \pm 0.2$ & $9.0 \pm 0.3$ & 9.0 & $5.5 \pm 0.1$ \\
\hline
\end{tabular}

(mean value \pm standard deviation) 


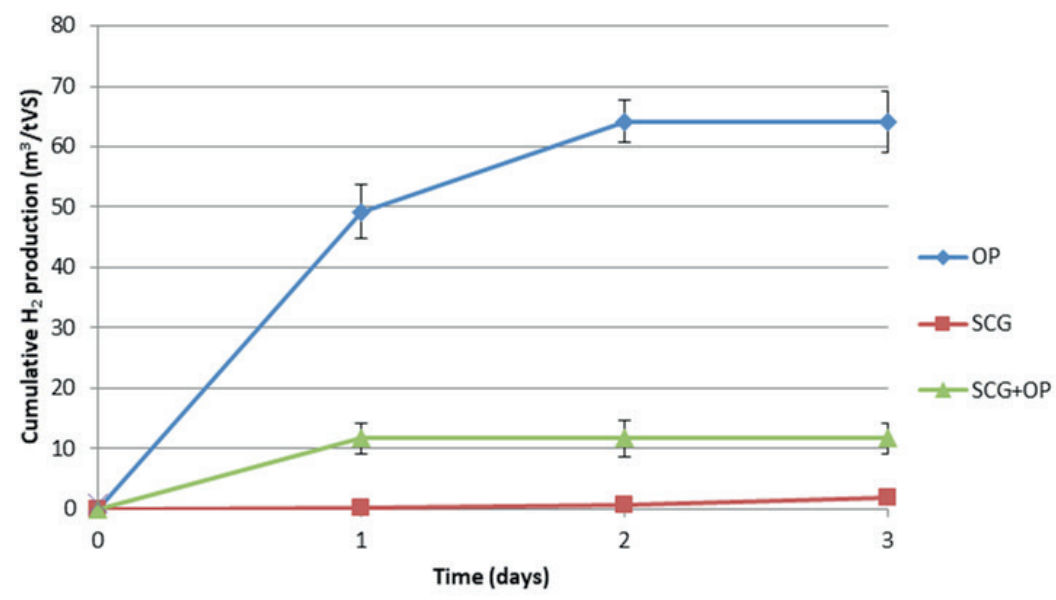

FIGURE 1: Cumulative hydrogen production during the acidogenic fermentation of spent coffee grounds (SCG), and orange peels (OP) as single substrates and as a mixture (SCG+OP).

broths was evaluated. The highest and considerable hydrogen yield of $64.1 \mathrm{~m}^{3} \mathrm{H}_{2} / \mathrm{tVS}$ was recorded from sample OP. $\mathrm{H}_{2}$ production was very low for samples SCG and SCG+OP. Almost zero hydrogen production occurred with SCG alone, with values of $11.6 \mathrm{~m}^{3} \mathrm{H}_{2} /$ tVS measured when fermenting SCG with OP. Thus, the addition of SCG led to an almost $82 \%$ decrease in hydrogen production with respect to OP.

In view of their high carbohydrate content, OP are a good source for hydrogen production and a good substrate for methane gas (El Kantar et al., 2018). It is likely that the high $\mathrm{pH}$ enhanced a faster and higher degradation rate; indeed, El Kantar et al. (2018) reported that catechin and epicatechin (two OP components) degradation is better achieved under basic conditions.

As reported in Figure 2, acetic and butyric acids were the most abundant products generated after three days acidogenic fermentation of OP and SCG+OP. In the case of pure SCG fermentation, the main VFA was acetate (23 $\mathrm{g} / \mathrm{L}$ ). OP showed the best yield in terms of total biological metabolite production, namely $62.6 \mathrm{~g} / \mathrm{L}$, where butyrate accounted for $57 \%$ of the total $(35.8 \mathrm{~g} / \mathrm{L})$. Butyric acid type fermentation, which in the present study occurred with OP but not with other samples, was generally reported to prevail at $\mathrm{pH}>6$ (Ren et al., 2007). Small amounts of ethanol
(3\%) and lactate (1\%) were included in OP fermentation products, although valerate production was virtually nil. Addition of SCG to OP led to an $11 \%$ decrease in product recovery. Notwithstanding this, acetate yield was significantly higher in the SCG+OP sample $(30.8 \mathrm{~g} / \mathrm{L})$ compared to OP $(22.1 \mathrm{~g} / \mathrm{L})$. Indeed, almost $80 \%$ of VFA from SCG alone was acetate, highlighting how SCG addition led to an increasingly aceto-oriented fermentation compared to mono-digestion of OP.

\subsubsection{Brewers' spent grains}

At the end of the acid and alkaline pre-treatments, $\mathrm{pH}$ had changed to 4 and 6.5, respectively (see Table 7), demonstrating the specific buffer capacity of BSG. Conversely, at the end of the acidogenic fermentation tests $\mathrm{pH}$ remained similar (between 5 and 6 ) among the four samples.

The production of hydrogen during acidogenic fermentation is shown in Figure 3. Hydrogen production reached a plateau after 2 days of acidogenic fermentation, but the test was continued until day 6 to monitor any late increase due to the fibrotic nature of the substrate. Gas quality, tested using a gas chromatograph, confirmed the ability of thermal pre-treatment of the inoculum to inhibit archaea activity, with methane concentration remaining below $3 \%$
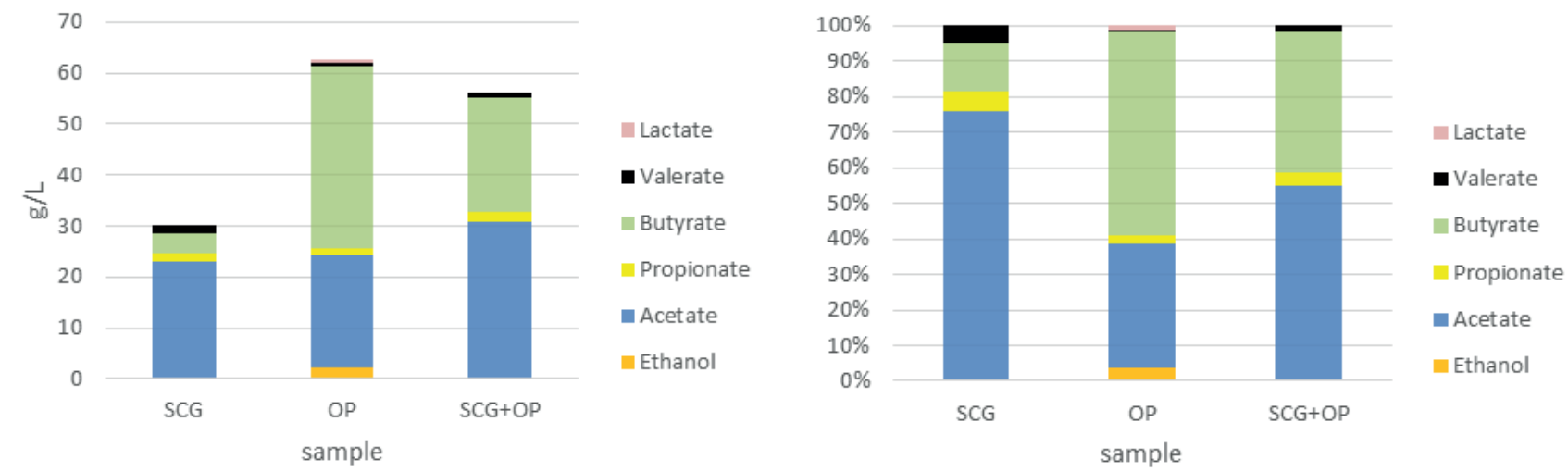

FIGURE 2: Actual values (on the left) and percentage distribution (on the right) of biological metabolites generated after 3 days acidogenic fermentation of spent coffee grounds (SCG) and orange peels (OP) as single substrates and as a mixture (SCG+OP). 
TABLE 7: Change observed in pH between the beginning (Pstart) and the end (Pend) of pre-treatments, and prior (AFstart) and subsequent to (AFend) acidogenic fermentation tests.

\begin{tabular}{|c|c|c|c|c|c|}
\hline \multirow{2}{*}{ Sample } & \multirow{2}{*}{ Pre-treatment } & \multicolumn{4}{|c|}{$\mathrm{pH}$} \\
\hline & & $\mathbf{P}_{\text {start }}$ & $\mathbf{P}_{\text {end }}$ & $\mathrm{AF}_{\text {start }}$ & $\mathrm{AF}_{\text {end }}$ \\
\hline BSG_a-s & Acid & $1.5 \pm 0.2$ & $4.0 \pm 0.2$ & 7.0 & $5 \pm 0.2$ \\
\hline BSG_r-s & none & $7.5 \pm 0.0$ & $5.0 \pm 0.1$ & 7.0 & $5.5 \pm 0.1$ \\
\hline BSG_b-n & Basic & $12.5 \pm 0.2$ & $6.5 \pm 0.2$ & 9.0 & $6 \pm 0.1$ \\
\hline BSG_r-n & none & $7.5 \pm 0.0$ & $5.0 \pm 0.1$ & 9.0 & $6 \pm 0.2$ \\
\hline
\end{tabular}

(mean value \pm standard deviation)

throughout the test (data not shown).

Overall, $\mathrm{H}_{2}$ production was very low. Indeed, the highest hydrogen yield of $7.2 \mathrm{~m}^{3} \mathrm{H}_{2} /$ tVS was recorded from sample BSG_r-s characterised by an initial pH of 7. Hydrogen yields of the other samples were lower compared to sample BSG_r-s. This suggests that BSG might not be an optimum choice if the goal was to maximise hydrogen production, irrespective of pre-treatment or initial $\mathrm{pH}$.

Alkaline pre-treatment was previously reported to be effective in the production of $\mathrm{H}_{2}$ from BSG (Behmel et al., 1993; Ravindran et al., 2018; Kan et al., 2018); however, our results are at variance with those published by Fan et al. (2006) who reported much higher hydrogen yields after acid pre-treatment, reaching $68.6 \mathrm{~m}^{3} \mathrm{H}_{2} / \mathrm{tVS}$.

As reported in Figure 4, the most abundant products detected after six days acidogenic fermentation of BSG were acetic and butyric acids, in agreement with results reported by Fan et al. (2006). The production of propionate (between 2 and $8 \%$ ) and valerate (less than $9 \%$ ) was very low, while ethanol and lactate were not detectable in any of the samples. Ethanol and lactate are easily degradable under neutral conditions and can therefore be assumed to have been metabolized (Liang and Wan, 2015), thus contributing to VFA production. The highest total amount of biological metabolites, $62.0 \mathrm{~g} / \mathrm{L}$, was achieved in sample BSG_b-n which underwent alkaline pre-treatment and was fermented at initial $\mathrm{pH}$ 9; this sample also displaced the highest acetate yield (36.7 g/L). Sample BSG_a-s (fermentation at $\mathrm{pH} 7$ after acid pre-treatment) revealed the highest butyrate production of $19.3 \mathrm{~g} / \mathrm{L}$.

It was interesting to observe how only alkaline pre-treatment ensured a $20 \%$ higher VFA generation (mainly acetate) compared to the untreated sample (BSG_r-n), while acid pre-treatment seemed to slightly reduce VFA occurrence compared to the untreated sample BSG_r-s.

Regardless of whether pre-treatment had been applied or not, acidogenic fermentation performed at initial $\mathrm{pH} 9$ yielded better than fermentation at initial $\mathrm{pH} 7$.

Considering that the best VFA yield is even higher than the highest production of biological metabolites from food waste $(58.1 \mathrm{~g} / \mathrm{L}$ ) at the same S/I ratio (Giotto et al., 2018c), BSG may be considered a good VFA feedstock, particularly after alkaline pre-treatment. However, when comparing our results with the findings of other studies present in the literature, a lack of agreement is evident. Liang and Wan (2015) reported that the optimal fermentation time was around 6 days, with lactate being the most dominant metabolite ( 9.2 $\mathrm{g} / \mathrm{L}$ ) under alkaline conditions. Moreover, they mentioned that neutral $\mathrm{pH}$ favoured longer chain VFA production (Liang and Wang, 2015), which did not occur in our tests.

\subsection{Discussion}

OP and BSG were shown to be particularly suitable substrates for the recovery of biological monomers by



FIGURE 3: Cumulative hydrogen production during the acidogenic fermentation of brewers' spent grains at pH 7 following acid pre-treatment (BSG_a-s), at pH 7 without pre-treatment (BSG_r-s), at pH 9 after basic pre-treatment (BSG_b-n), and at pH 9 without pre-treatment (BSG_r-n). 



FIGURE 4: Actual values (on the left) and percentage distribution (on the right) of biological metabolites generated after 6 days acidogenic fermentation of brewers' spent grains at initial pH 7 after acid pre-treatment (BSG_a-s), pH 7 without pre-treatment (BSG_r-s), pH 9 after basic pre-treatment (BSG_b-n), and pH 9 without pre-treatment (BSG_r-n).

means of acidogenic fermentation. SCG alone appeared to produce a lower amount of total VFA, but a considerable levels of acetic acid, comparable to those obtained with OP and BSG. The molecules (VFA, ethanol, and lactic acid) produced during acidogenic fermentation could be exploited for a variety of uses ranging from energy production, to bio-polymer production, or as intermediate feedstock chemicals (Girotto et al., 2017a).

With a focus on bio-plastic production, these results suggest that OP and BSG represent biomasses particularly suited to use in implementing biorefinery approaches in which VFA is valorised to produce polyhydroxyalkanoates (PHAs). In addition to the range of potential applications as a versatile resource (Girotto et al., 2017c), SCG are particularly suitable for use in aceto-oriented processes aimed at the production of polyvinyl acetate (PVA).

The results further reveal that a basic (alkaline) $\mathrm{pH}$ is beneficial in improving acetate production and percentage of the same in total VFA, in agreement with observations made by Dahiya et al. (2015) and Gameiro et al. (2016). A basic $\mathrm{pH}$ was also found to be beneficial in propionate production as reported in Figure 4 for BSG, in agreement with Gameiro et al. (2016). An alkaline redox microenvironment enhances the hydrolysis of carbohydrates and proteins by triggering ionization of the charged groups (e.g. carboxylic groups) and therefore facilitating the solubility and availability of fermentable matter (Dahiya et al., 2015).

Another possible explanation for the high recovery of total biological metabolites from the tested substrates lies in their good buffer capacity, as attested to by the observation of a moderate (not too low) pH at the end of acidogenic fermentation tests (see Tables 6 and 7). Indeed, when the fermented biodegradable waste prevents a sudden drop in $\mathrm{pH}$ values, maintaining a favourable $\mathrm{pH}$ range for acidogenic bacterial activity and preventing inhibition issues, VFA generation is promoted (Gameiro et al., 2016).

\section{CONCLUSIONS}

The acidogenic fermentation of organic residues from beverage production has been identified as a potential means of recovering biological monomers for use in the production of bio-plastics, or other high-value usages. Beverage production residues are characterised by an abundant availability and current lack of holistic valorisation approaches; they may indeed be considered as suitable feedstock for the implementation of biorefinery strategies undertaken for the purpose of recovering biological monomers and producing bio-plastics. To this regard, three high-volume beverage production residues were assessed, namely spent coffee grounds (SCG), orange peels (OP), and brewers' spent grains (BSG), providing positive results.

All three substrates yielded significant amounts of valuable biological monomers in acidogenic fermentation, with highest yield of total monomers obtained with OP and BSG. BSG and SCG benefited from alkaline pre-treatment prior to acidogenic fermentation. Initiation of acidogenic fermentation at a $\mathrm{pH}$ of 9 was shown to be suitable when using an inoculum that had been thermally pre-treated to inhibit methanogenic archaea and to halt the anaerobic digestion process at the acidogenic fermentation step.

The results obtained highlight how OP and BSG are particularly promising for use in implementing pathways for the high-quality valorisation of VFA, such as the production of PHAs (polyhydroxyalkanoates). SCG are more suitable for aceto-oriented strategies, such as the production of PVA (polyvinyl acetate). The production of bio-plastics therefore is feasible from all three studied biomasses, although via different routes.

To conclude, an experimental scale-up, completed by the practical recovery and utilisation of the produced biological metabolites, and a cost and benefit analysis should be undertaken to verify the sustainability of the whole biorefinery approach.

\section{REFERENCES}

Agler, M., Wrenn, B., Zinder, S., Angenent, L., 2011. Waste to bioproduct conversion with undefined mixed cultures: the carboxylate platform. Trends Biotechnol.

Akunna, J.C., 2015. Anaerobic treatment of brewery wastes. Brewing Microbiology. 407-424.

Aliyu, S., Bala, M., 2011. Brewers' spent grain: a review of its potentials and applications. African Journal of Biotechnology, 10(3), 324-331. 
Alibardi, L., Favaro, L., Lavagnolo, M.C., Basaglia, M., Casella, S., 2012. Effects of heat treatment on microbial communities of granular sludge for biological hydrogen production. Water Sci. Technol. 66(7), 1483-1490.

APHA/AWWA/WEF, 2012. Standard Methods for the Examination of Water and Wastewater, Standard Methods. doi:ISBN 9780875532356

Behmel, U., Leupold, G., Vieweger, S., 1993. Production of biogas from plant waste. Part 1. Optimized hydrolysis of the lignocellulosic components in spent grain. Chemie, Mikrobiologie, Technologie der Lebensmittel 15, 55-61.

Bicas, J.L., Fontanille, P., Pastore, G.M., Larroche, C., 2008. Characterization of monoterpene biotransformation in two pseudomonads. J. Appl. Microbiol. 105, 1991-2001. https://doi.org/10.1111/ j.1365-2672.2008.03923.x.

Calabrò, P.S., Panzera, M.F., 2018a. Anaerobic digestion of ensiled orange peel waste: preliminary batch results. Thermal Science and Engineering Progress.

Calabrò, P.S., Paone, E., Komilis, D., 2018b. Strategies for the sustainable management of orange peel waste through anaerobic digestion. Journal of environmental management, 212, 462-468.

Chaturvedi, V., Verma, P., 2013. An overview of key pretreatment processes employed for bioconversion of lignocellulosic biomass into biofuels and value added products. Biotech. 3, 415-431.

Dahiya, S., Sarkar, O., Swamy, Y.V., Mohan, S.V., 2015. Acidogenic fermentation of food waste for volatile fatty acid production with co-generation of biohydrogen. Bioresource technology, 182, 103113.

da Silva, F.F.M., Ferreira, D.A., Monte, F.J.Q., de Mattos, M.C., de Lemos, T.L.G., 2016. The orange peel as biocatalyst for the hydrolysis of esters. Industrial Crops and Products, 84, 22-27.

El Kantar, S., Boussetta, N., Rajha, H. N., Maroun, R.G., Louka, N., Vorobiev, E., 2018. High voltage electrical discharges combined with enzymatic hydrolysis for extraction of polyphenols and fermentable sugars from orange peels. Food Research International.

Fan, Y. T., Zhang, G. S., Guo, X. Y., Xing, Y., Fan, M.H., 2006. Biohydrogen-production from beer lees biomass by cow dung compost. Biomass and Bioenergy, 30(5), 493-496.

FAO - Food and Agriculture Organization, 2015. FAOSTAT emissions database: agriculture. http://faostat3.fao.org/download/Q/QC/E

Fillaudeau, L., Blanpain-Avet, P., Daufin, G., 2006. Water, wastewater and waste management in brewing industries. Journal of cleaner production, 14(5), 463-471.

Firestone, D., 1994. Official methods and recommended practices of the American Oil Chemists' Society. AOCS Press. 4th edn, 2-5. doi:http://dx.doi.org/10.1002/0471740039.vec0152.

Foss, S., Heyen, U., Harder, J., 1998. Alcaligenes defragrans sp. nov., description of four strains isolated on alkenoic monoterpenes ((+)-menthene, a-pinene, 2-carene and a-phellandrene) and nitrate. Syst. Appl. Microbiol. 21, 237-244.

Gameiro, T., Lopes, M., Marinho, R., Vergine, P., Nadais, H., Capela, I., 2016. Hydrolytic-acidogenic fermentation of organic solid waste for volatile fatty acids production at different solids concentrations and alkalinity addition. Water, Air, \& Soil Pollution, 227(10), 391.

Gáspár, M., Kálmán, G., Réczey, K., 2007. Corn fiber as a raw material for hemicellulose and ethanol production. Process Biochem. 42 1135-1139.

Girotto, F., Lavagnolo, M. C., Pivato, A., Cossu, R., 2017a. Acidogenic fermentation of the organic fraction of municipal solid waste and cheese whey for bio-plastic precursors recovery-Effects of process conditions during batch tests. Waste Management, 70, 71-80.

Girotto, F., Lavagnolo, M. C., Pivato, A., 2017b. Spent Coffee Grounds Alkaline Pre-treatment as Biorefinery Option to Enhance their Anaerobic Digestion Yield. Waste and Biomass Valorization, 1-6.

Girotto, F., Pivato, A., Cossu, R., Nkeng, G. E., Lavagnolo, M.C., 2017c. The broad spectrum of possibilities for spent coffee grounds valorisation. Journal of Material Cycles and Waste Management, 20(1), 695-701.

Girotto, F., Lavagnolo, M. C., Pivato, A., 2017d. Spent coffee grounds alkaline pre-treatment as biorefinery option to enhance their anaerobic digestion yield. Waste and Biomass Valorization, 1-6.

Heyen, U., Harder, J., 1998. Cometabolic isoterpinolene formation from isolimonene by denitrifying Alcaligenes defragrans. FEMS Microbiol. Lett. 169, 67-71.

International Coffee Organization, 2018. Coffee Market Report - June 2018. http://www.ico.org/documents/cy2017-18/cmr-0618-e.pdf Accessed July 2018.
Kan, X., Zhang, J., Tong, Y.W., Wang, C H., 2018. Overall evaluation of microwave-assisted alkali pretreatment for enhancement of biomethane production from brewers' spent grain. Energy Conversion and Management, 158, 315-326.

Karmee, S.K., 2017. A spent coffee grounds based biorefinery for the production of biofuels, biopolymers, antioxidants and biocomposites. Waste Manage. 72, 240-254.

Kendal, N.T., 1994. Barley and malt. In: Hardwick, W.A. (Ed.), Handbook of Brewing. Marcel Dekker, New York, pp. 109-120.

Kimball, D.A., 1999. Citrus Processing: A Complete Guide. 2nd ed. Aspen Publishers Inc., Gaithersburg, Maryland (USA).

Koppar, A., Pullammanappallil, P., 2013. Anaerobic digestion of peel waste and wastewater for on site energy generation in a citrus processing facility. Energy 60, 62-68.

Kovalcik, A., Kucera, D., Matouskova, P., Pernicova, I., Obruca, S., Kalina, M., Marova, I., 2018. Influence of removal of microbial inhibitors on PHA production from spent coffee grounds employing Halomonas halophila. Journal of Environmental Chemical Engineering, 6(2), 3495-3501.

Kunze, W., 1996. In: Mieth, H.O. (Ed.), Technology Brewing and Malting-International Edition. VLB, Berlin. 726.

Lavagnolo, M.C., Girotto, F., Rafieenia, R., Danieli, L., Alibardi, L., 2018. Two-stage anaerobic digestion of the organic fraction of municipal solid waste e Effects of process conditions during batch tests. Renewable Energy, 126, 14-20.

Liang, S., Wan, C., 2015. Carboxylic acid production from brewers' spent grain via mixed culture fermentation. Bioresource technology, $182,179-183$.

Macheiner, D., Adamitsch, B.F., Karner, F., Hampel, W.A., 2003. Pre-treatment and hydrolysis of brewers' spent grains. Engineering in life sciences, 3(10), 401-405

Martín, M. A., Fernández, R., Gutiérrez, M. C., Siles, J.A., 2018. Thermophilic anaerobic digestion of pre-treated orange peel: Modelling of methane production. Process Safety and Environmental Protection, 117, 245-253

Mussatto, S.I., Roberto, I.C., 2004. Alternatives for detoxification of dilute-acid lignocellulosic hydrolyzates for use in fermentative process: a review. Bioresource Technology 93, 1-10.

Mussatto, S.I., Dragone, G., Roberto, I.C., 2006. Brewers' spent grain: generation, charac-teristics and potential applications. Journal of Cereal Science, 43, 1-14.

Mussatto, S.I., Machado, E.M.S., Martins, S., Teixeira, J.A., 2011. Production, composition, and application of coffee and its industrial residues. Food Bioprocess Tech. 4, 661-672.

Obruca, S., Benesova, P., Kucera, D., Petrik, S., Marova, I., 2015. Biotechnological conversion of spent coffee grounds into polyhydroxyalkanoates and carotenoids. New Biotechnol. 32 (6), 569-574.

Pan, J., Zhang, R., El-Mashad, H.M., Sun, H., Ying, Y., 2008. Effect of food to microorganism ratio on biohydrogen production from food waste via anaerobic fermentation. Int. J. Hydrogen Energy, 33, 6968-6975.

Park, J., Kim, B., Lee, J.W., 2016. In-situ transesterification of wet spent coffee grounds for sustainable biodiesel production. Bioresour. Technol. 221, 55-60.

Pellera, F.M., Santori, S., Pomi, R., Polettini, A., Gidarakos, E., 2016. Effect of alkaline pretreatment on anaerobic digestion of olive mill solid waste. Waste Manag. 58, 160-168.

Qureshi, A. S., Khushk, I., Naqvi, S. R., Simiar, A. A., Ali, C. H., Naqvi, M., Rehan, M., 2017. Fruit Waste to Energy through Open Fermentation. Energy Procedia, 142, 904-909.

Ravindran, R., Jaiswal, S., Abu-Ghannam, N., Jaiswal, A.K., 2018. A comparative analysis of pretreatment strategies on the properties and hydrolysis of brewers' spent grain. Bioresource technology, 248, 272-279.

Ren, N.Q., Chua, H., Chan, S.Y., Tsang, Y.F., Wang, Y.J., Sin, N., 2007. Assessing optimal fermentation type for bio-hydrogen production in continuous-flow acidogenic reactors. Bioresource Technology, 98(9), 1774-1780.

Ruiz, B., Flotats, X., 2014. Citrus essential oils and their influence on the anaerobic digestion process: an overview. Waste Manag. 34, 2063-2079.

Smith, 0., 2017. The surprising countries that consume the most beer per capita. The Telegraph.

Stojceska, V., Ainsworth, P., Plunkett, A., Ibanog`lu, S., 2008. The recycling of brewers' processing by-product into ready-to-eat snacks using extrusion technology. Journal of Cereal Science, 47(3), 469479 . 
Statista, 2018. Consumer Goods \& FMCG. Food \& Nutrition https://www. statista.com/statistics/425760/consumption-of-fruit-juice-italy/

Steel, R., Torrie, J., 1980. Principles and procedures of statistics: a biometrical approach. 161.

Taherzadeh, M.J., Karimi, K., 2008. Pretreatment of lignocellulosic wastes to improve ethanol and biogas production: a review. Int. J. Mol. Sci. 9, 1621-51.

Torres, M. L., Lloréns, M.D.C.E., 2008. Effect of alkaline pretreatment on anaerobic digestion of solid wastes. Waste Management, 28(11), 2229-2234.

Van Ginkel, S.W., Oh, S.E., Logan, B.E., 2005. Biohydrogen gas production from food processing and domestic wastewaters. Int. J. Hydrog. En. 30, 1535-1542.

Wilkinson, L., 1992. SYSTAT for Windows: statistics, graphics, data, getting started, version 5 .
Yang, L.F., Cao, J., Jin, Y.C., Chang, H.M., Jameel, H., Phillips, R., Li, Z.Z., 2012. Effects of sodium carbonate pretreatment on the chemical compositions and enzymatic saccharification of rice straw. Bioresour. Technol. 124, 283-291.

Yin, J., Yu, X., Zhang, Y., Shen, D., Wang, M., Long, Y., Chen, T., 2016b. Enhancement of acidogenic fermentation for volatile fatty acid production from food waste: effect of redox potential and inoculum. Bioresour. Technol. 216, 996-1003.

Zema, D. A., Fòlino, A., Zappia, G., Calabrò, P. S., Tamburino, V., Zimbone, S. M., 2018. Anaerobic digestion of orange peel in a semi-continuous pilot plant: An environmentally sound way of citrus waste management in agro-ecosystems. Science of The Total Environment, 630, 401-408. 